\title{
Monitoring Pembangkit Listrik Tenaga Angin Menggunakan Arduino Berbasis GUI Matlab
}

\author{
Nila Gusriani ${ }^{1}$, Muldi Yuhendri² \\ 1,2 Jurusan Teknik Elektro, Universitas Negeri Padang \\ Jl. Prof. Dr. Hamka, Air Tawar Padang, Sumatera Barat, 25132, Indonesia \\ Nilagusriani12@gmail.com ${ }^{1}$,muldiy@ft.unp.ac.id²
}

\begin{abstract}
Wind power is a type of renewable energy power plant that is starting to develop in Indonesia. This plant uses wind turbines to convert wind power into mechanical power that will drive the electric generator. The generators used in this wind power plant have limited capabilities. In order to avoid operations that exceed the capacity of the generator, it is necessary to monitor and protect the components of the wind power plant. This study proposes a wind power generator monitoring system using the Arduino MKR 1000 based on the Matlab Graphical User Interface (GUI). Wind power plant parameters that are monitored are wind speed, turbine rotation speed and generator output power. The wind power generator monitoring system made in this study was tested on a wind power plant using a horizontal axis wind turbine and a permanent magnet synchronous generator. The results of the tests conducted show that the proposed wind power generator monitoring system is capable of monitoring wind power plant parameters well..
\end{abstract}

Keywords - Wind power plant, wind turbine, arduino MKR 1000, GUI Matlab, generator power.

\begin{abstract}
Abstrak - Pembangkit listrik tenaga angin adalah salah satu jenis pembangkit listrik energi terbarukan yang mulai berkembang di Indonesia. Pembangkit ini menggunakan turbin angin untuk mengkonversikan daya angin menjadi daya mekanik yang akan menggerakan generator listrik. Generator yang digunakan pada pembangkit listrik tenaga angin ini memiliki kemampuan yang terbatas. Agar tidak terjadi operasi yang melampaui batas kemampuan generator, maka perlu dilakukan monitoring dan proteksi terhadap komponen komponen yang ada pada pembangkit listrik tenaga angin tersebut. Penelitian ini mengusulkan sistem monitoring pembangkit listrik tenaga angin menggunakan Arduino MKR 1000 berbasis Graphical User Interface (GUI) Matlab. Parameter pembangkit listrik tenaga angin yang dimonitor adalah kecepatan angin, kecepatan putaran turbin dan daya output generator. Alat sistem monitoring pembangkit listrik tenaga angin yang dibuat dalam penelitian ini diujicobakan pada pembangkit listrik tenaga angin yang menggunakan turbin angin sumbu horizontal dan generator sinkron jenis magnet permanen. Hasil pengujian yang dilakukan menunjukan bahwa alat sistem monitoring pembangkit listrik tenaga angin yang diusulkan telah mampu memonitor parameter pembangkit listrik tenaga angin dengan baik.
\end{abstract}

Kata kunci- Pembangkit listrik tenaga angin, turbin angin, arduino MKR 1000, GUI Matlab, daya generator.

\section{Pendahuluan}

Salah satu energi terbarukan yang bisa dimanfaatkan sebagai sumber pembangkit tenaga listrik adalah energi angin. Pembangkit listrik tenaga angin umum memiliki dua konverter energi utama untuk mengkonversikan energi angin menjadi energi listrik, yaitu turbin angin untuk mengkonversikan daya angin menjadi daya mekanik yang akan menggerakan generator dan generator listrik untuk mengkonversikan daya mekanik dari turbin angin menjadi daya listrik [1]-[5]. Daya output yang dihasilkan generator ditentukan oleh daya angin yang ditangkap turbin, dimana daya angin ini ditentukan oleh kecepatan angin yang mengenai turbin angin [6]-[7]. Kecepatan angin ini tidak bisa dikendalikan, sementara turbin angin dan generator yang ada pada pembangkit listrik tenaga angin memiliki kemampuan yang terbatas. Generator tidak boleh beroperasi di atas nilai ratingnya, baik rating daya maupun kecepatan putarannya. Untuk menjaga keselamatan operasional pembangkit listrik tenaga angin ini, maka perlu dilakukan monitoring dan proteksi terhadap turbin angin dan generator, sehingga pembangkit tidak bekerja di luar batas kemampuannya [8].

Berdasarkan kemampuan generator, pengoperasian turbin angin dapat dibagi menjadi empat zona operasi yaitu, zona 1, 2, 3 dan zona 4 [9]-[10]. Zona 1 atau zona cut in merupakan zona dimana kecepatan angin yang mengenai turbin masih di bawah kecepatan angin yang dibutuhkan untuk menggerakan turbin angin. Berarti di dalam zona ini turbin angin tidak bekerja atau beroperasi. Pada zona 2, kecepatan angin berada diatas zona 1 dan di bawah zona 3 , yang mana daya mekanik yang dihasilkan turbin angin masih di bawah rating daya generator. Pada zona 3 dimana daya mekanik yang dihasilkan turbin angin masih dapat dikendalikan, pada zona ke 4 merupakan zona yang memiliki kecepatan angin yang sudah melampaui kemampuan turbin angin, maka dari itu operasi pembangkit listrik tenaga angin harus dihentikan, yang disebut sebagai zona cut off. Berdasarkan zona 
operasi ini, maka pembangkit hanya beroperasi pada zona 2 dan 3.

Untuk mengetahui zona operasi pembangkit listrik tenaga angin, maka perlu dilakukan sistem monitoring pada pembangkit tersebut. Beberapa penelitian telah dilakukan untuk sistem monitoring pembangkit listrik tenaga angin ini, seperti monitoring kecepatan dan arah angin berbasis web [11], monitoring kecepatan dan arah angin berbasis komputer [12], monitoring kecepatan angin berbasis wireless menggunakan arduino uno [13] dan monitoring pembangkit listrik tenaga angin berbasis smartphone android [14]. Semua penelitian yang telah dilakukan oleh peneliti lain memiliki kelebihan dan kekurangan. Penelitian ini mengusulkan sistem monitoring pembangkit listrik tenaga angin menggunakan arduino MKR 1000 berbasis GUI Matlab. Kelebihan dari alat monitoring ini adalah dapat menampilkan data dalam bentuk angka dan grafik secara real time. Parameter pembangkit listrik tenaga angin yang dimonitor adalah kecepatan angin yang mengenai turbin, kecepatan putaran poros turbin dan daya yang dihasilkan oleh generator.

\section{Metode}

Penelitian tentang sistem monitoring pembangkit listrik tenaga angin ini dilakukan dengan cara eksperimen di laboratorium. Eksperimen yang dilakukan mencakup perancangan, pembuatan dan pengujian alat. Alat sistem monitoring dibuat untuk pembangkit listrik tenaga angin yang menggunakan turbin angin horizontal dengan generator jenis generator sinkron magnet permanen. Alat sistem monitoring yang dirancang dalam penelitian ini dapat dilihat pada blok diagram yang ditunjukan oleh Gambar 1.

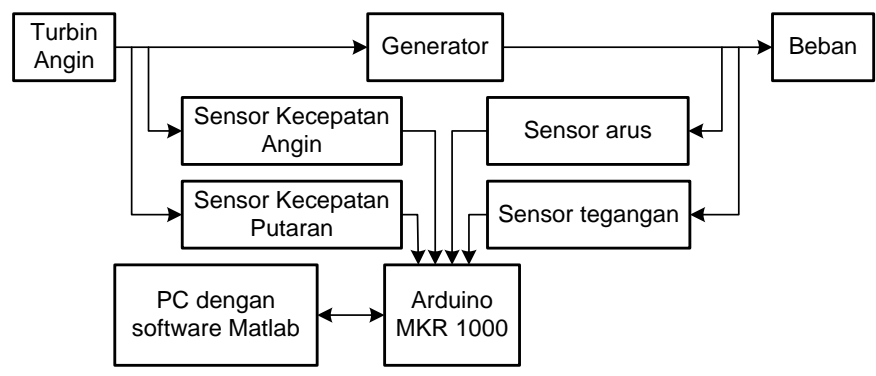

Gambar 1. Blok diagram sistem monitoring pembangkit listrik tenaga angin

Gambar 1 menunjukan bahwa data-data pembangkit listrik tenaga angin yang akan dimonitor diperoleh dari sensor. Data kecepatan angin diperoleh dari sensor kecepatan angin yang dipasang di depan turbin angin. Data kecepatan putaran diperoleh dari sensor kecepatan putaran yang dipasang pada poros turbin angin. Data daya output generator diperoleh dari sensor arus dan tegangan yang dipasang pada beban. Sensor kecepatan angin dan sensor kecepatan putaran dirancang menggunakan rotary encoder. Sensor ini terdiri dari sepasang photo diode, piringan yang memiliki celah serta rangkaian pembangkit dan penerima sinyal [15]. Gambar 2 menunjukan skema rangkaian rotary encorder yang digunakan dalam penelitian ini.

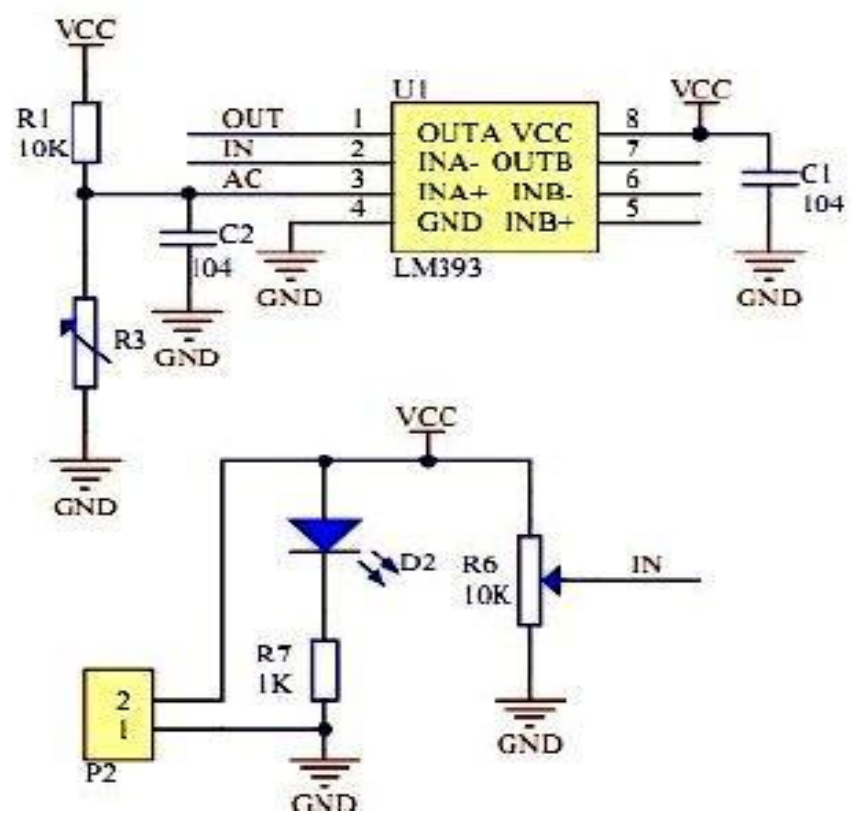

Gambar 2. Skema rangkaian rotary encoder

Rotary encoder ini akan menghasilkan pulsa per menit sesuai dengan jumlah celah piringan dan kecepatan putaran . Berdasarkan pulsa permenit ini dapat dihitung kecepatan putaran permenit atau root per minute (rpm). Gambar 3 menunjukan sensor rotary encoder yang dipasang pada poros turbin angin untuk mendapatkan data kecepatan putaran turbin.

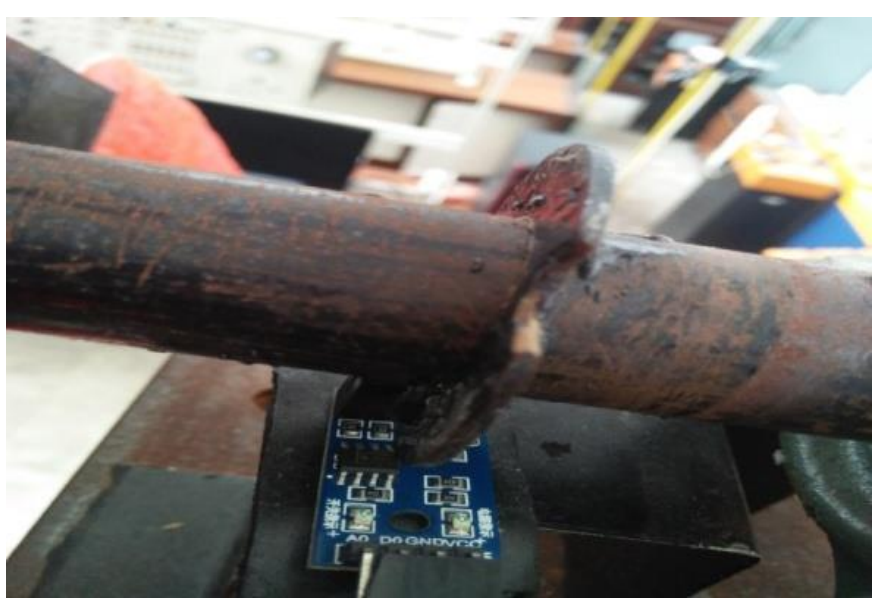

Gambar 3. Pemasangan rotary encoder pada poros turbin angin 
Kecepatan angin merupakan kecepatan linear yang dapat diperoleh dengan mengkonversikan kecepatan putaran yang diperoleh dari rotary encoder menjadi kecepatan linear. Untuk mendapatkan data kecepatan angin, maka rotary encoder yang digunakan ditambahkan tiga buah mangkok-mangkok pada porosnya, sehingga akan diperoleh kecepatan putaran. Data kecepatan putaran ini kemudian dikonversikan menjadi kecepatan linear yang merupakan data kecepatan angin. Sensor kecepatan angin ini dipasang di depan turbin angin, sehingga akan menangkap kecepatan angin yang dihasilkan oleh blower. Gambar 4 menunjukan posisi pemasangan rotary encoder untuk mendapatkan data kecepatan angin.

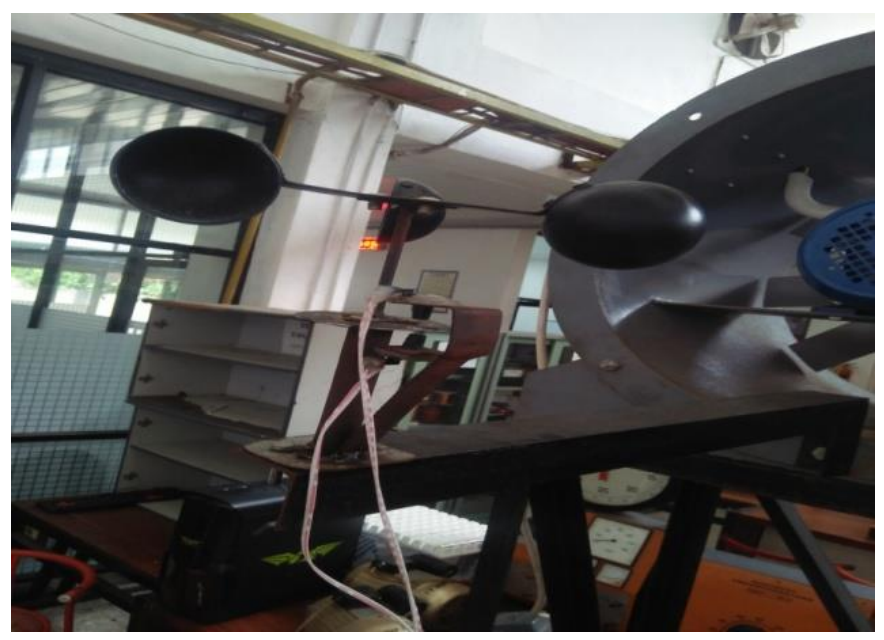

Gambar 4. Pemasangan sensor kecepatan angin

Daya output generator diperoleh dengan mengalikan data arus searah dan tegangan searah yang diperoleh dari sensor. Generator yang digunakan dalam penelitian ini adalah generator sinkron magnet permanen tiga fasa. Oleh sebab itu, sebelum dipasang sensor, terlebih dahulu generator dipasang penyearah tiga fasa. Generator ini dihubungkan dengan beban resistor untuk mendapatkan data daya outputnya.

Semua data-data yang diperoleh dimasukan ke dalam arduino MKR 1000 untuk diolah dan ditampilkan pada GUI Matlab. Gambar 5 menunjukan hardware rangkaian sistem monitoring pembangkit listrik tenaga angin yang diusulkan dalam penelitian ini.

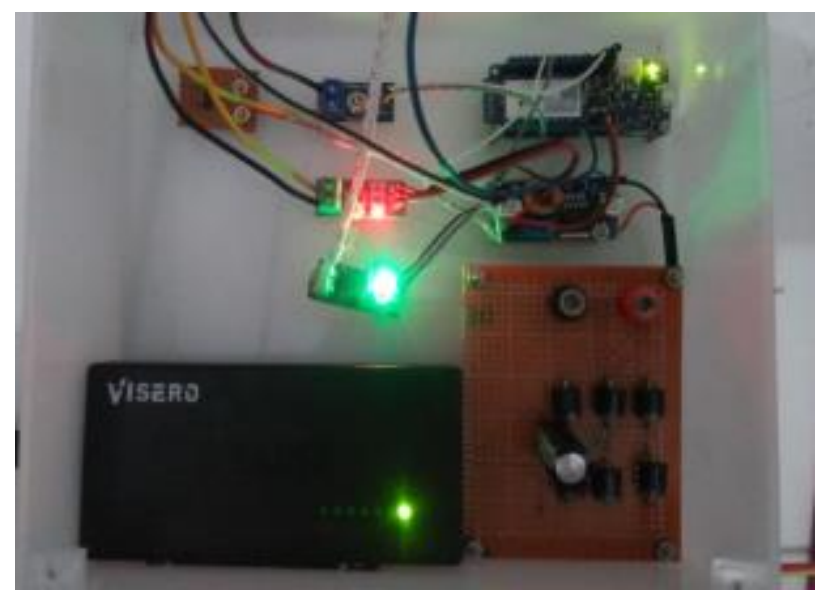

Gambar 5. Hardware monitoring pembangkit listrik tenaga angin

Data-data kecepatan angin, kecepatan putaran turbin dan data daya output generator yang diolah pada arduino di tampilkan dalam bentuk grafik dan angka pada GUI Matlab. Gambar 6 menunjukan tampilan sistem monitoring pembangkit listrik tenaga angin pada GUI Matlab.

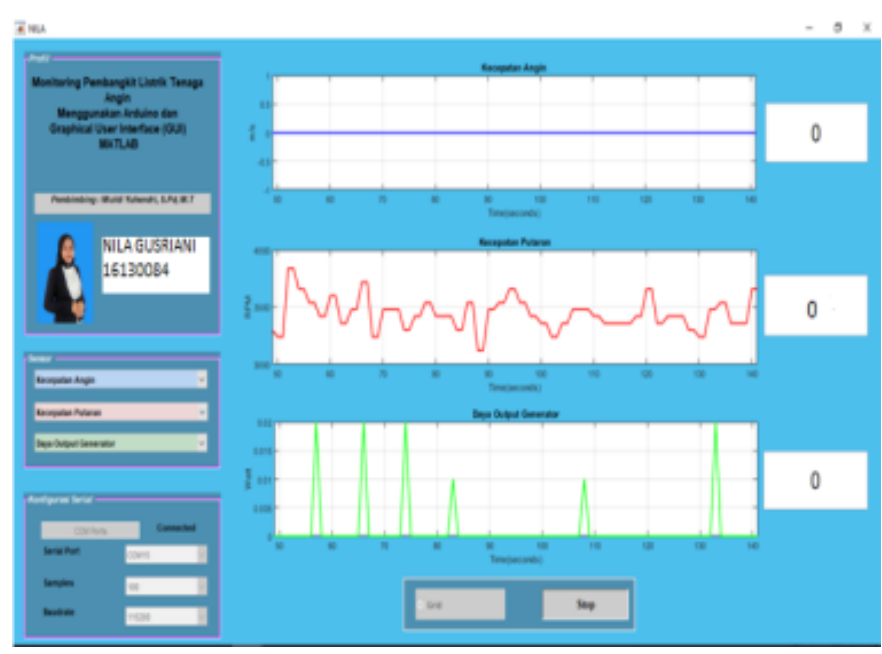

Gambar 6. Tampilan sistem monitoring pada GUI Matlab

\section{HASIL DAN PEMBAHASAN}

Sistem monitoring yang dibuat dalam penelitian ini diuji di laboratorium. Gambar 7 menunjukan situasi proses pengujian alat yang dibuat. Dalam pengujian ini, sebagai penghasil kecepatan angin adalah blower yang digerakan oleh motor induksi tiga fasa, seperti yang ditunjukan pada Gambar 7 di bawah ini. Pengujian alat sistem monitoring ini dilakukan dengan kecepatan angin yang bervariasi dengan cara memvariasikan tegangan motor blower menggunakan autotraformator. Data pengujian berupa data kecepatan angin, kecepatan putaran dan daya output generator akan ditampilkan dalam bentuk angka dan grafik pada layar monitor PC. 


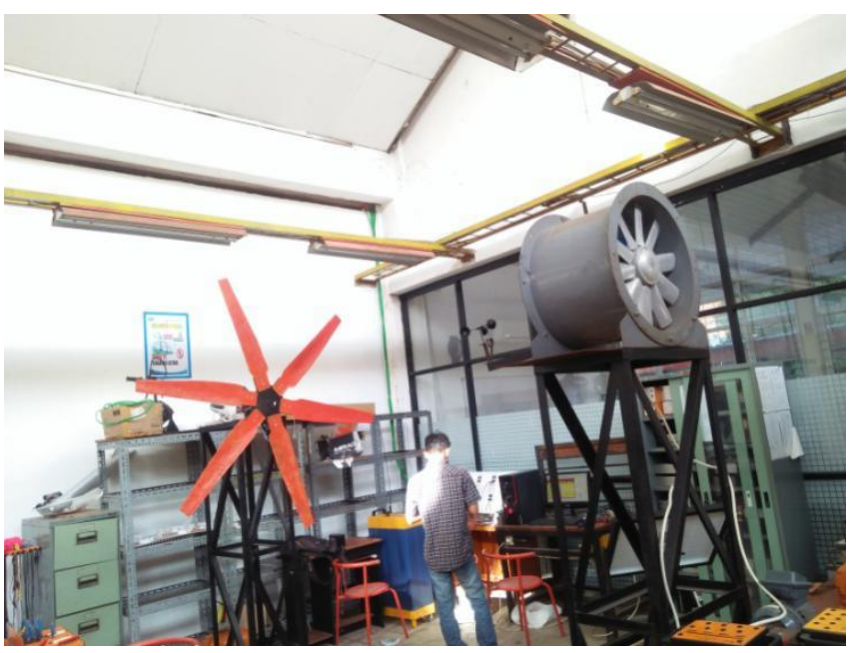

Gambar 7. Pengujian alat

Data pada alat sistem monitoring ini akan divalidasi dengan membandingkan data yang ditampilkan pada GUI Matlab dengan data yang diperoleh pada alat ukur. Gambar 8 dan Tabel 1 menunjukan hasil pengujian untuk data kecepatan angin.

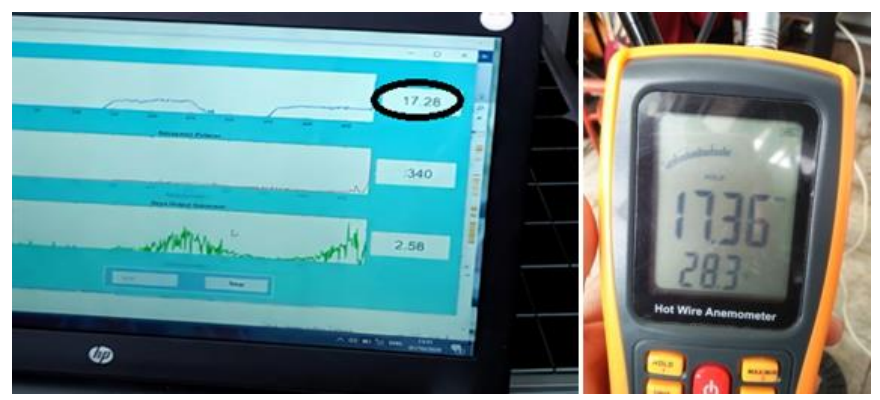

Gambar 8. Hasil pengujian kecepatan angin

TABEL I. Hasil Pengujian Kecepatan Angin

\begin{tabular}{|c|c|c|}
\hline \multirow{2}{*}{ Percobaan } & \multicolumn{2}{|c|}{ Data Kecepatan Angin (m/detik) } \\
\cline { 2 - 3 } & Tampilan GUI & Alat Ukur \\
\hline 1 & 7.08 & 7.07 \\
\hline 2 & 10.49 & 10.21 \\
\hline 3 & 17.36 & 17.28 \\
\hline
\end{tabular}

Hasil pengujian kecepatan angin pada Gambar 8 dan Tabel 1 menunjukan bahwa alat sistem monitoring pembangkit listrik tenaga angin yang dibuat dalam penelitian ini telag bekerja dengan baik dalam menampilkan data kecepatan angin, dimana data yang ditampilkan pada GUI telah mendekati sama dengan data pada anemometer. Hal yang sama juga diperoleh untuk pengujian kecepatan putaran, seperti yang ditunjukan oleh Gambar 9 dan Tabel 2.

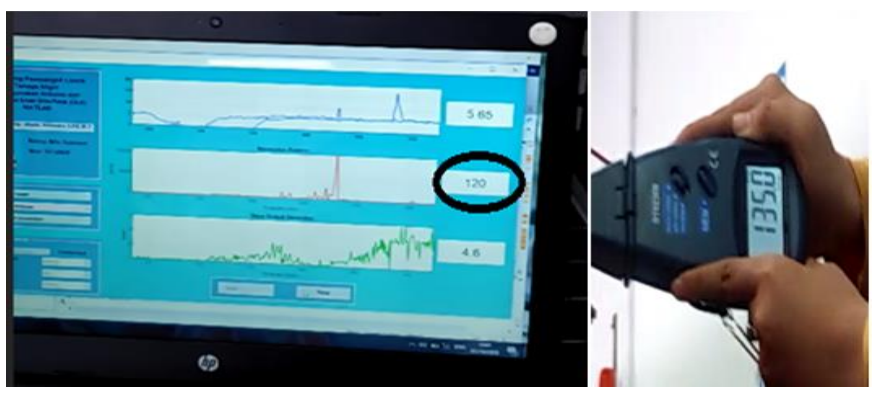

Gambar 9. Hasil pengujian kecepatan putaran

TABEL II. Hasil PEngujIan Kecepatan Putaran

\begin{tabular}{|c|c|c|}
\hline \multirow{2}{*}{ Percobaan } & \multicolumn{2}{|c|}{$\begin{array}{c}\text { Tata Kecepatan putaran (rpm) } \\
\text { GUI }\end{array}$} \\
\hline 1 & 135.0 & Alat Ukur \\
\hline 2 & 213.7 & 120 \\
\hline 3 & 380 & 180 \\
\hline
\end{tabular}

Gambar 9 menunjukan bahwa data kecepatan putaran pada layar monitor adalah sebesar $135 \mathrm{rpm}$ pada pengujian pertama, sedangkan hasil pengukuran dengan tachometer diigital sebesar $135 \mathrm{rpm}$. Hasil ini menunjukan bahwa data pada alat sistem monitoring sudah mendekati sama dengan data yang ada pada alat ukur. Hal ini juga dapat pada pengujian kedua dan ketiga. Hasil ini menunjukan bahwa alat yang dibuat sudah mampu memonitor kecepatan putaran turbin dengan baik.

Gambar 10 dan menunjukan hasil pengujian untuk daya output generator. Hasil ini juga menunjukan bahwa data yang diperoleh pada GUI Matlab juga sudah mendekati sama dengan data yang diperoleh dari alat ukur.
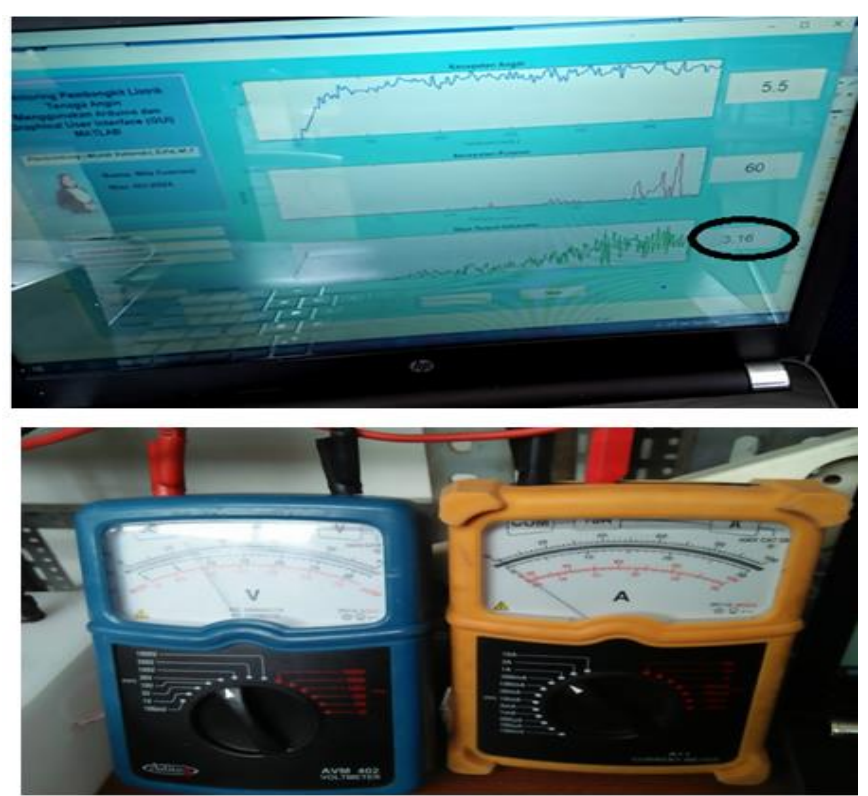

Gambar 10. Hasil pengujian daya output generator 
Semua hasil pengujian menunjukan bahwa data yang dihasilkan sudah mendekati sama, baik dari alat ukur anemometer,tachometer,volt dan amperemeter sudah menunjukan angka yang sama dengan data pada GUI yang ada pada PC. Hasil ini menunjukan bahwa rancangan sistem monitoring turbin angin dengan menggunakan arduino MKR 1000 berbasis GUI Matlab sudah dapat bekerja dengan baik dalam memonitor kecepatan angin, kecepatan putaran dan daya outpur generator.

\section{Penutup}

Penelitian ini mengusulkan sistem monitoring pembangkit listrik tenaga angin menggunakan arduino MKR 1000 berbasis GUI Matlab. Parameter turbin angin yang dimonitor adalah kecepatan angin, kecepatan putaran dan daya output generator. Data-data dari parameter pembangkit tersebut diperoleh dengan menggunakan sensor rotary encorder, sensor arus dan tegangan. Rancangan alat sistem monitoring pembangkit listrik tenaga angin ini diuji dengan kecepatan angin yang bervariasi. Hasil pengujian menunjukan bahwa sistem monitoring pembangkit listrik tenaga angin yang diusulkan dalam penelitian ini telah bekerja dengan baik, dimana data yang ditampilkan pada GUI Matlab sudah mendekati sama dengan data yang diperoleh pada alat ukur.

\section{REFERENSI}

[1] M. Yuhendri, Aslimeri and M. Muskhir, "Optimum Torque Control of Stand Alone Wind Turbine Generator System Fed Single Phase Boost Inverter," in Proc. IEEE 2nd ICon EEI, pp. 148-153, 2018.

[2] A. Tummala, R. K. Velamati, D. K. Sinha, V. Indraja and V. H Krishna, "A review on small scale wind turbines," Renewable and Sustainable Energy Reviews," vol. 56, pp 1351-1371, April 2016.

[3] M. Yuhendri, M. Muskhir and Taali, "A novel optimum tip speed ratio control of low speed wind turbine generator based on type-2 fuzzy system," Bulletin of Electrical Engineering and Informatics, vol. 8, no. 4, pp. 1189-1197, 2019.

[4] S. S. Laxminarayan, M. Sing, A. H. Saifee and A. Mittal, "Design, modeling and simulation of variable speed Axial Flux Permanent Magnet Wind Generator," Sustainable Energy Technologies and Assessments, vol. 19, pp. 114-124, February 2017

[5] M. Yuhendri dan Aslimeri, "Optimum torque control of direct driven wind energy conversion sistems fed sparse matrix converter," Journal of Electrical Sistem, vol. 14, no. 3, pp. 12-25, September 2018.
[6] A. Bonfiglio, F. Delfino, F. G. Longatt, and R. Procopio, "Steady-state assessments of PMSGs in wind generating units," Electrical Power and Energy Systems, vol. 90, pp. 87-93, September 2017

[7] M. Yuhendri, M. Ashari, M. H. Purnomo, "A Novel Sensorless MPPT Control For Wind Turbine Generators Using Very Sparse Matrix Converter Based on Hybrid Inteligent Control," Int. Review of Electrical Engineering, vol. 10, no. 2, pp. 233-243, 2015.

[8] J.F. Manwell, J.G. McGowan dan A. L. Rogers. Wind Energy Explained : Theory, Design and Applicationsecond edition. West Sussex : John Willey \& Sons Ltd, 2009

[9] M. Yuhendri, M. Ashari, M. H. Purnomo, "Adaptive type-2 fuzzy sliding mode control for grid-connected wind turbine generator using very sparse matrix converter," Int. Journal of Renewable Energy Research, vol. 5, no. 3, pp. 668-676, 2015.

[10] D. Kumar and K. Chatterjee, "A Review of conventional and advanced MPPT algorithms for wind energy systems," Renewable and Sustainable Energy Reviews, vol. 55, pp. 957-970, March 2016.

[11] Y. Pramono, Warsito dan Syafriadi, "Monitoring data kecepatan dan arah angin secara real time melalui web," Jurnal Teori dan Aplikasi Fisika, vol. 4, pp. 221-226, Juli 2016

[12] A. R. Hakim, Litasari dan Djuniadi, "Alat ukur kecepatan dan arah angin berbasis komputer," Jurnal Teknik Elektro, vol. 1, pp. 71-77, Januari 2009.

[13] O. Derek, E. K. Allo dan N. M. Tulung, "Rancang bangun alat monitoring kecepatan angin dengan koneksi wireless menggunakan arduino uno," E-Journal Teknik Elektro dan Komputer, vol. 5, pp. 1-7, Juli 2016.

[14] R. Y. Pratama dan M. Yuhendri, "Monitoring Turbin Angin Menggunakan Smartphone Android," Jurnal Teknik Elektro dan Vokasional (JTEV), vol. 6, no. 2, pp. 64-71, 2020.

[15] R. Prabowo, A. Muida dan R. Adriat, "Rancang bangun alat pengukur kecepatan angin berbasis mikrokontroler ATMega 328P," Prisma Fisika, vol. 6, pp. 94-100, 2018

[16] M. Yuhendri, M. Ashari dan M. H. Purnomo, "Maximum output power tracking of wind turbine using intelligent control," Telkomnika, vol. 9, no, 2, pp. 217, 2011

[17] M. Yuhendri, M. Ashari dan M.H. Purnomo, "Maximum output power tracking dengan metode direct field oriented control pada pembangkit listrik tenaga angin stand alone," in Proc. Seminar Nasional Fakultas Teknologi Industri (SNFTI) XIV, July 2009, pp. B01.1 - B01.10

[18] Aswardi, M. Yuhendri dan D. T. Yanto, Teknik Elektronika Daya Indonesia : IRDH Book Publisher, 2020.

\section{Biodata Penulis}

Nila Gusriani, Lahir di Tapan tahun 1998. Menyelesaikan studi DIV Teknik Elektro Industri pada Jurusan Teknik Elektro Fakultas Teknik Universitas Negeri Padang.

Muldi Yuhendri, lahir di Kampung Aur, 13 Desember 1981. Sarjana Pendidikan Teknik Elektro, Universitas Negeri Padang tahun 2005, S2 Teknik Elektro Sistem Tenaga, ITS tahun 2009, S3 Ilmu Teknik Elektro, ITS tahun 2017. Staf pengajar pada jurusan teknik elektro FT UNP sejak tahun 2006 sampai sekarang. 